\title{
ANALISIS KEBERHASILAN SERVIS ATLET TENIS PADA KEJUARAAN POPDA KOTA SEMARANG TAHUN 2018
}

\author{
Rahmat Hidayat \\ Jurusan Pendidikan Jasmani Kesehatan dan Rekreasi, Universitas PGRI Semarang, Semarang, Indonesia \\ *rahmamatt@gmail.com
}

(Received: July 2018 / Revised: August 2018 / Accepted: September 2018)

\begin{abstract}
ABSTRAK : Olahraga tenis merupakan olahraga yang sudah dimainkan oleh anak usia dini hingga dewasa. Olahraga ini juga sudah mulai menjadi olahraga prestasi maka tidak sedikit pertandingan tenis yang diadakan di Indonesia. Dalam penelitian ini peneliti memfokuskan pada analisis keberhasilan servis yang dilakukan atlet pada kejuaraan POPDA kota Semarang. Yang bertujuan untuk mengetahui tingkat keberhasilan servis didalam pertandingan. Dan dapat menjadi bahan evaluasi bagi pelatih. Jenis penelitian ini yaitu penelitian deskriptif yang hanya menggambarkan dan menjelaskan suatu fenomena. Hasil dari penelitian ini menunjukkan bahwa atlet yang mengikuti kejuaraan POPDA kota Semarang masih banyak melakukan kesalahan ini dilihat dari data yang diambil yaitu 795 kali melakukan fault. 141 kali melakukan double dan hanya 13 kali melakukan ace total terdapat 949 kali percobaan melakukan servis. Dari data yang didapat hendaknya atlet dan pelatih dapat memperbaiki servis yang masih menjadi kelemahan.
\end{abstract}

KATA KUNCI : Analisis, Keberhasilan, Servis, Tenis.

ABSTRACTS : Tennis is a sport that has been played by early childhood to adulthood. This sport has also started to become a sports achievement then not a few tennis matches held in Indonesia. In this study the researchers focused on the analysis of the success of service performed athletes at the POPDA championship Semarang city. Which aims to determine the level of service success in the game. And can be an evaluation material for the coach. This type of research is descriptive research that only describes and explains a phenomenon. The results of this study indicate that athletes who follow the championship POPDA Semarang city still make a lot of mistakes is seen from the data taken that is 795 times the fault. 141 times double and only 13 times ace total there are 949 times trial service. From the data obtained should athletes and coaches can improve the service that is still a weakness.

KEYWORD :

Analysis, Success, Service, Tennis.

\section{PENDAHULUAN}

Tenis merupakan olahraga yang sudah menjadi lifestyle dikalangan masyarakat. Olahraga ini sangat sering mengadakan kejuaraan baik dilevel daerah, nasional bahkan internasional. Di Indonesia olahraga ini sudah di pertandingkan dari usia 8, 10, 12, 14, 16, 18 tahun hingga senior. Animo masyarakat sangat baik sekali dalam mengikuti kejuaraan tenis di Indonesia terbukti dari setiap pertandingan yang diselenggarakan dan TDP (Tournament di akui pelti) rata-rata peserta yang mengikuti kejuaraan tidak kurang dari 100 orang putra dan putri. usia anak-anak mulai bermain tenis mulai dari 6 sampai 8 tahun, ada juga yang mulai latihan di usia 10 tahun. Ketika anak-anak diusia 6 sampai 8 tahun latihan yang diberikan adalah latihan basic seperti control bola dan memantulkan bola, setelah itu barulah masuk ke teknik dasar forehand dan backhand (Durovic, 2008). Dalam bermain tenis pukulan pertama untuk memulai permainan adalah servis, pukulan ini sangat penting untuk dikuasai oleh pemain karena merupakan senjata awal untuk mendapatkan point tanpa melakukan rally (Elliott, 2014). Didalam pertandingan tenis servis dapat memberikan tekanan mental terhadap lawan, ketika pemain melakukan servis dan lawan tidak dapat mengembalikanya maka pemain akan 
merasa sangat tertekan dengan situasi yang sedang terjadi (Behm, 2008).

Kejuaraan seperti pekan olahraga pelajar daerah merupakan salah satu bentuk kejuaraan yang dapat memberikan evaluasi terhadap kelemahan dan kekurangan atlet, terutama pada teknik dasar servis. Pelatih dapat melihat kelemahan dan kekurangan atlet ketika bertanding di POPDA sebelum atlet bertanding di kejuaraan nasional bahkan untuk mempersiapkan atlet di kejuaraan pekan olahraga nasional (POPNAS). Pada kejuaraan POPDA di kota Semarang yang akan diikuti oleh pemain terbaik dari perwakilan kecamatan kota masing-masing ini merupakan kesempatan bagi pelatih untuk melihat kemampuan atletnya selama berlatih yang telah dilakukan. Berdasarkan dari pengamatan yang peneliti lakukan dari beberapa pertandingan banyak sekali atlet melakukan servis double sehingga lawan dapat dengan mudah mendapatkan point tanpa melakukan pukulan maupun rally hal inilah yang harus menjadi perhatian bagi pelatih untuk memperbaiki kelemahan tersebut. Keefektifan gerakan dapat menghasilkan servis yang baik (Alim, 2010) Maka perlu dilakukan penelitian untuk menganalisis keberhasilan servis atlet tenis pada kejuaraan POPDA kota Semarang tahun 2018. Servis dapat menjadi kelebihan bagi seorang atlet apabila dapat menguasainya dengan baik (Carl, 2012).

Berdasarkan latar belakang masalah di atas, maka dapat ditarik sebuah permasalahan yaitu Keberhasilan atlet dalam melakukan servis pada saat kejuaraan POPDA kota Semarang dan Kekurangan atlet dalam melakukan servis pada saat kejuaraan POPDA kota Semarang.

\section{METODE PENELITIAN}

Jenis penelitian ini adalah penelitian deskriptif, dimana peneliti hanya sampai taraf mengetahui gambaran dari suatu objek. Menurut Suharsimi Arikunto (2006 : 139) penelitian deskriptif adalah penelitian yang hanya menggambarkan keadaan atau status fenomena. Pada penelitian deskriptif kali ini peneliti menggunakan metode observasi sebagai alat bantu untuk memperoleh data. Observasi adalah kegiatan pengamatan meliputi kegiatan pemuatan perhatian terhadap suatu objek dengan menggunakan seluruh alat indra (Suharsimi Arikunto 2006 : 199).

Populasi dalam penelitian ini adalah atlet tenis yang bertanding pada kejuaraan POPDA kota Semarang yang terdiri dari 13 atlet putri SD, 19 atlet putra SD, 9 atlet putra SMP, 4 altet putri SMP. Sampel dalam penetilian ini adalah semua atlet yang mengikuti kejuaraan POPDA kota Semarang atau bisa juga disebut dengan populasi sampel. Jumlah pertandingan yang akan dilaksanakan pada tingkat SD putri ada 12 pertandingan, SD putra 18 pertandingan, SMP putri 12 pertandingan dan SMP putra 8 pertandingan. Khusus untuk SMP putri sistem pertandingan setengah kompetisi karena jumlah peserta hanya 4 orang sedangkan SD putra, SD putri dan SMP putra di pertandingkan dengan sistem gugur.

\section{HASIL}

Berdasarkan dari data yang didapat terdapat hasil yang kurang baik dari analisis keberhasilan servis untuk mendapatkan point. Terdapat total 949 kali percobaan servis yang dilakukan hanya $1,3 \%$ yang dapat menghasilkan point, $14,8 \%$ yang kehilangan point dari melakukan kesalahan dalam melakukan servis dan $83,7 \%$ kesalahan dalam melakukan servis pertama atau yang disebut dengan fault. Hal ini menunjukkan bahwa servis belum bisa dijadikan senjata untuk mendapatkan point oleh atlet sehingga servis perlu menjadi perhatian khusus para pelatih agar atlet dapat meningkatkan kemampuannya. Data tersebut dilihat dari tabel dibawah ini : 
Tabel 1. Hasil pengambilan data servis

\begin{tabular}{|c|c|c|c|c|c|}
\hline No & NAMA & $\begin{array}{c}\text { JENIS } \\
\text { KELAMIN }\end{array}$ & FAULT & ACE & DOUBLF \\
\hline 1 & SHA & $\mathbf{P}$ & 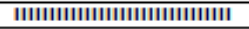 & & IIIIII \\
\hline 2 & AP & $\mathbf{P}$ & IIIIIIIIIIIIIIIIIIIII & & IIIII \\
\hline 3 & RA & $\mathbf{P}$ & 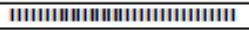 & II & IIIIIIII \\
\hline 4 & $\mathbf{C l}$ & $\mathbf{P}$ & IIIIIIIIIIIIIIIIIIIIIIIIIII & & IIIIIIII \\
\hline 5 & DU & $\mathrm{L}$ & IIIIIIIIIIIIIIIIIIIIIIIIIII & & \\
\hline 6 & RAF & $L$ & IIIIIIIIIIIIIIIIIIIIIIIIII & & \\
\hline 7 & MA & $\mathbf{L}$ & IIIIIIIIIIIIIIII & & IIII \\
\hline 8 & AD & $\mathrm{L}$ & IIIIIIIIIIIIIIIIIIIIIIIIII & 1 & IIIIIIIIIIII \\
\hline 9 & RFI & $L$ & IIIIIII & & II \\
\hline 10 & AL & $\mathbf{P}$ & IIIIIIIIIIIIIIIIIIIIIIII & & III \\
\hline 11 & $Z A$ & $\mathbf{P}$ & IIIIIIIIIIII & & 1 \\
\hline 12 & CR & $\mathrm{L}$ & ||||||||||||||||||||||||||||||||||||||||| & III & IIIIIIIIII \\
\hline 13 & BR & $\mathrm{L}$ & IIIIIIIIIIIIIIIIIIIIIIIIIIIIIIIIII & IIII & 1 \\
\hline 14 & AD & $\mathbf{L}$ & IIIIIIIIIIIIIIIIIII & & IIIIII \\
\hline 15 & MA & $\mathrm{L}$ & IIIIIIIIIIIIIIIIIII & & 1 \\
\hline 16 & RL & $\mathrm{L}$ & IIIIIIIIIIIIIIIIIIIIIIIII & 1 & IIIII \\
\hline 17 & RI & $\mathbf{P}$ & 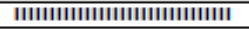 & & \\
\hline 18 & AL & $\mathbf{P}$ & IIIIIIIII & & 1 \\
\hline 19 & $\mathrm{CE}$ & $\mathbf{P}$ & II & & \\
\hline 20 & RDT & $\mathrm{L}$ & IIIIIIIIIIIIIIIIIIIII & & IIIII \\
\hline 21 & AAS & $\mathrm{L}$ & IIIIIIIIIIIIIIIIIII & & IIIIIIII \\
\hline 22 & VEL & $\mathbf{P}$ & IIII & & \\
\hline 23 & OLE & $\mathbf{P}$ & III & & \\
\hline 24 & SAA & $\mathbf{P}$ & IIIIIIIIIIIIIIIIIIIIII & $T$ & IIIIIIII \\
\hline 25 & VRO & $\mathbf{P}$ & IIIIIIIIIIIIIIIIIIII & & IIIIIII \\
\hline 26 & ENA & $\mathbf{P}$ & IIIIIIIIIIIIIIIII & & IIIIIIIII \\
\hline 27 & $\mathrm{NHA}$ & $\mathbf{P}$ & IIIIIII & & \\
\hline 28 & M HA & $\mathrm{L}$ & IIIIIIIIIIIIIIIIII & & \\
\hline 29 & SITA & $L$ & IIIIIII & & \\
\hline 30 & ACEL & $\mathrm{L}$ & IIIIIIIIIIIIIIIII & & IIIIII \\
\hline 31 & BA & $\mathrm{L}$ & IIIIIIIIIIIIIII & & IIII \\
\hline 32 & EYT & $L$ & IIIIIIIIIIIIIIIIIIII & 1 & III \\
\hline 33 & $\mathrm{IH}$ & $\mathrm{L}$ & IIIIIIIIIIII & & IIIIIII \\
\hline 34 & MOU & $\mathbf{L}$ & IIIIIIIIIII & & \\
\hline 35 & BRI & $\mathrm{L}$ & I||I||||||||||||||||||||||||||||||||||||| & & IIIIIIII \\
\hline 36 & FZA & $\mathrm{L}$ & IIIIIIIIII & & IIII \\
\hline 37 & ITA & $\mathbf{P}$ & IIII & & \\
\hline 38 & ERI & $\mathbf{P}$ & IIIIIIIIIII & & \\
\hline 39 & REL & $\mathrm{L}$ & IIIIIIIIIIIIIIIIIIIIIIIIIIIIIII & & \\
\hline 40 & $\mathrm{JE}$ & $L$ & IIIIIIIIIIIIIIIII & & \\
\hline 41 & RIN & $L$ & IIIIIIIIIIIIIIIIIIIIIIIII & & \\
\hline 42 & AIN & $\mathrm{L}$ & IIIIIIIIIIII & & IIIIII \\
\hline 43 & NIA & $\mathbf{P}$ & IIIIIIII & & \\
\hline \multicolumn{3}{|c|}{ JUMLAH } & 795 & 13 & 141 \\
\hline
\end{tabular}

Dari data diatas dapat ditarik juga kesimpulan dari rata-rata dari setiap kesalahan yang dilakukan mulai dari fault, ace dan double. Dari 43 sampel yang diteliti melakukan fault sebanyak 795, ace sebanyak 13 dan double sebanyak 141. Rata-rata dari yang dilakukan oleh atlet dapat dilihat di tabel berikut ini :

Tabel 2. Statistics

\begin{tabular}{lrrr}
\hline & FAULT & ACE & DOUBLE \\
\hline $\mathbf{N} \quad$ Valid & 43 & 7 & 27 \\
\hline \multicolumn{1}{c}{ Missing } & 0 & 36 & 16 \\
\hline Mean & 18.30 & 1.86 & 5.22 \\
\hline Median & 18.00 & 1.00 & 6.00 \\
\hline Mode & $7^{\mathrm{a}}$ & 1 & $6^{\mathrm{a}}$ \\
\hline
\end{tabular}

\section{PEMBAHASAN}

Penelitian ini menunjukkan bahwa atlet masih sangat banyak melakukan kesalahan ketika melakukan servis. Servis yang seharusnya bisa menjadi senjata untuk mendapatkan point malah menjadi suatu kelemahan yang dapat dengan mudah dimanfaatkan oleh lawan untuk mendapatkan point. Ketika melakukan servis pertama masih banyak yang fault, memang dari beberapa atlet yang melakukan servis, servis pertama akan menjadi spekulasi untuk mendapatkan point padahal di era tenis modern sekarang servis pertama bukan hanya menjadi spekulasi saja melainkan sudah dilatih khusus untuk mendapatkan point dengan gratis, walaupun lawan dapat mengembalikan servis pertama namun bola yang dikembalikan akan tanggung di tengah lapangan sehingga dapat dengan mudah dipukul untuk menghasilkan point. Dari penelitian ini juga menunjukkan bahwa semakin sering atlet melakukan fault maka peluang untuk melakukan servis double pun semakin besar, ini bisa juga dilihat dari faktor psikologi ketika atlet tersebut sering melakukan kesalahan atau fault maka dapat mengurangi rasa kepercayaan diri sehingga besar kemungkinan untuk melakukan servis double. Dari data yang diambil menunjukkan bahwa atlet masih banyak memberikan point gratis yaitu melakukan kesalahan dengan servis double. Di era tenis modern sekarang ketika atlet melakukan servis maka dia harus mendapatkan game tersebut jangan sampai game tersebut diambil oleh lawan, karena servis merupakan senjata awal untuk mendapatkan point, sehingga tidak sedikit pemain profesional mendapatkan game hanya melakukan servis saja. Dari penelitian ini sevis ace hanya 13 kali saja dari total 949 kali percobaan servis yang dilakukan, ini menunjukkan bahwa atlet masih belum terlatih untuk melakukan servis.

\section{SIMPULAN DAN REKOMENDASI}

Penelitian ini kiranya dapat memberikan masukkan kepada pelatih maupun atlet untuk memperhatikan servis yang dilakukan, karena servis juga sangat penting didalam pertandingan. Kelemahan servis dapat dimanfaatkan dengan 
mudah oleh lawan, sehingga kelemahan ini harus diperbaiki. Untuk melakukan latihan servis hendaknya dimulai dari tahapan-tahapan yang mudah terlebih dahulu kemudian sedang dan baru ketingkat yag lebih sulit (Emery, 2010). Mulai dari latihan melempar bola, kemudian mengayunkan raket kebelakang, setelah itu perkenaan bola keraket hingga ke gerakan lanjutan. Lakukan servis di depan net terlebih dahulu sekitar 2 sampai 3 meter didepan net, kemudian secara bertahap mundur 1 meter dan seterusnya hingga kegaris belakang lapangan. Hal ini harus dilakukan secara bertahap mengingat perlu adanya adaptasi otot lengan untuk melakukan servis apalagi kalau atletnya masih usia dini. Yang biasanya dilakukan oleh beberapa pelatih hanya melatih pukulan forehand, backhand dan volley, ketika mulai mendekati pertandingan baru dilatih servis hal inilah yang menyebabkan kelemahan atlet ketika melakukan servis, karena kurangnya latihan servis. Servis juga terbagi menjadi tiga yaitu servis slice, flat dan top spin (Carre, 2014). Servis yang paling mudah dikuasai adalah servis slice. Tingkat keberhasilan dalam melakukan servis slice sangat tinggi biasanya servis ini diajarkan pertama kali, kalau untuk servis flat harus memiliki tinggi badan dan power yang besar. Selain power penempatan bola dalam melakukan servis juga sangat penting. Akurasi ditambah power akan menghasilkan servis yang sangat sulit dikembalikan bahkan bisa menjadi ace.

\section{UCAPAN TERIMAKASIH}

Dalam penelitian ini tentunya peneliti dibantu dari berbagai pihak baik bantuan secara fisik maupun bantuan secara pikiran. Bersamaan dengan ini peneliti mengucapkan terimakasih yang sebesar-besarnya kepada teman-teman wasit jawa tengah yang telah memberikan bantuan selama penelitian yang dilakukan. Dan juga kepada pelatih tenis Indonesia om Deddy Prasetyo yang selalu membimbing dan mengarahkan peneliti dalam melakukan analisis dan memberikan masukan yang sangat luar biasa kepada peneliti. Dan juga tidak lupa peneliti mengucapkan terimakasih kepada kedua orangtua yang selalu memberikan semangat kepada peneliti dalam menyelesaikan penelitian.

\section{REFERENSI}

Alim. (2010). Efektivitas Pukulan Teknik Servis Pada Atlet Senior DIY. Yogyakarta: Universitas Negeri Yogyakarta.

Arikunto, Suharsimi. (2010). Prosedur Penelitian: Suatu Pendekatan Praktik. Jakarta: Rineka Cipta.

Behm. (2008). "' Kinesiological Analysis Of The Tennis service". Canada: Faculty Of Physcal Activity Studies University Of Regina. NSCA Journal. Volume 10. 5 (1988).

Carre, Matt j. (2014). "Friction at the tennis shoecourt interface: how biomechanically informed lab-based testing can enhance understanding" International Journal of Sport Kinesiologica 72 ( 2014 ) $883-888$

Carl, Payton j. (2012). "Motion Analysis Using Video" International Journal of Sport Biomechanical. 6(2012) PE 118.

Durovic. (2008). "Kinematic Analysis Of The Tennis Serve In Young Tennis Player". Croatia : Faculty of Kinesiology, University of Zagreb. International Journal of Sport Kinesiologica. 2(2008) 2: 50-56.

Elliott, Nathan. (2014). "Markerless tracking of tennis racket motion using a camera" International Journal of Sport Kinesiologica. 72 ( 2014 ) $344-349$.

Emery. (2010). "Biomechanical Analysis of the Tennis Serve". International Journal of Sport Biomechanical. 6(2001) PE 117. 